\title{
Microwave hyperthermia enhances the sensitivity of lung cancer cells to gemcitabine through reactive oxygen species-induced autophagic death
}

\author{
YANG YANG $^{1}$, CHUN-LI YANG $^{2}$, ZHEN-JIANG ZHAO $^{3}$, XIAO-XIAO ZUO $^{1}$, \\ TIAN-SONG LIANG ${ }^{1}$, YA YANG ${ }^{1}$, SHENG-LIN MA ${ }^{4}$ and DAO-KE YANG ${ }^{1}$ \\ ${ }^{1}$ Department of Radiation Oncology, The First Affiliated Hospital of Zhengzhou University, Zhengzhou, Henan 450000; \\ ${ }^{2}$ Gynecology and Obstetrics, The Third Affiliated Hospital of Zhengzhou University, Zhengzhou, Henan 450052; \\ ${ }^{3}$ Emergency Department, Children's Hospital Affiliated to Zhengzhou University, Zhengzhou, Henan 450053; \\ ${ }^{4}$ Center for Translational Medicine, Affiliated Hangzhou First People's Hospital, \\ Zhejiang University School of Medicine, Hangzhou,
}

Zhejiang 310006, P.R. China

Received August 30, 2018; Accepted March 15, 2019

DOI: $10.3892 /$ or.2019.7085

\begin{abstract}
The pleiotropic effects of hyperthermia on cancer cells have been well documented, and microwave hyperthermia (MWHT) has been widely applied for multifarious cancer treatment. However, the mechanisms underlying the anticancer effect of MWHT combined with gemcitabine (GEM) remain poorly understood. The aim of the present study was to investigate the role of autophagy in the thermo-chemotherapy of human squamous cell lung carcinoma cells. It was observed that MWHT combined with GEM potently suppressed the viability of NCI-H2170 and NCI-H1703 cells, and induced G0/G1 cell cycle arrest. Notably, MWHT with GEM induced autophagy, as indicated by the formation of autophagic vacuoles, downregulation of p62 and upregulation of light chain 3-II. It was further demonstrated that the autophagy was due to the production of reactive oxygen species (ROS), whereas N-acetyl cysteine, an ROS scavenger, attenuated the level of autophagy. However, when the autophagy
\end{abstract}

Correspondence to: Professor Dao-Ke Yang, Department of Radiation Oncology, The First Affiliated Hospital of Zhengzhou University, 1 Jianshe East Road, Zhengzhou, Henan 450000, P.R. China E-mail: 15903650068@163.com

Professor Sheng-Lin Ma, Center for Translational Medicine, Affiliated Hangzhou First People's Hospital, Zhejiang University School of Medicine, 261 Huansha Road, Shangcheng, Hangzhou, Zhejiang 310006, P.R. China

E-mail: mashenglin@medmail.com.cn

Key words: microwave hyperthermia, gemcitabine, autophagy, reactive oxygen species, phosphoinositide 3-kinase/protein kinase $\mathrm{B} /$ mammalian target of rapamycin, squamous cell lung carcinoma inhibitor 3-methyladenine was used, there was no significant change in the production of ROS. Furthermore, it was observed that MWHT combined with GEM downregulated the protein expression levels of phosphoinositide 3-kinase (PI3K), phosphorylated (p)-PI3K, protein kinase B (AKT), $\mathrm{p}$-AKT, mammalian target of rapamycin (mTOR), p-mTOR, phosphorylated S6 (pS6) and p70 S6 kinase, which are associated with autophagy. In addition, the results demonstrated that ROS served as an upstream mediator of PI3K/AKT/mTOR signaling. In light of these findings, the present study provides original insights into the molecular mechanisms underlying the cell death induced by MWHT combined with GEM, and this may be a promising approach for the treatment of human squamous cell lung carcinoma.

\section{Introduction}

Lung cancer is the main cause of cancer-associated mortality worldwide (1), and squamous cell lung carcinoma is one of the most common types of non-small-cell lung cancer (NSCLC). Despite treatment with surgical resection combined with chemotherapy and radiotherapy, patients with squamous cell lung carcinoma exhibit an overall 5-year survival of $<15 \%$ (2). Gemcitabine (GEM) is routinely used as the standard first-line treatment for advanced squamous cell lung carcinoma; however, the majority of the patients inevitably develop resistance to GEM, followed by tumor progression (3-5). Although molecular targeting drugs and immunotherapy have been beneficial in the treatment of lung adenocarcinoma, there is yet no clear targeted drug treatment for squamous cell lung carcinoma (6). Therefore, targeted prevention and treatment of peritoneal carcinomatosis from lung cancer is crucial for improving the quality of life and prognosis of patients.

Hyperthermia using a number of energy sources, such as ultrasound, laser, radiofrequency and microwaves, has long been investigated for cancer treatment (7). Microwave hyperthermia (MWHT), due to its low incidence of adverse 
reactions, easy clinical implementation and effectiveness in improving the results of traditional radiochemotherapy, has been widely used as an adjuvant cancer treatment. A large number of clinical studies have confirmed that MWHT can improve the prognosis of patients with cancer, including hepatic, breast, bladder and lung cancer (7-13). Indeed, the ability of MWHT to enhance the anticancer effects of chemotherapy is well known. It has previous been demonstrated that hyperthermia (conventional water bath) combined with GEM significantly inhibited the growth and proliferation of cancer cells, and promoted apoptotic cell death (14). However, traditional water bath hyperthermia only involves thermal effects, and its preclinical research is limited. To resolve this issue, our recent study (15) improved the feasibility and safety of this treatment by independently developing a novel, non-invasive hyperthermia instrument (patent no. CN-204824903-U) based on the use of microwaves with 433-MHz frequency for the treatment of NSCLC in vitro and in vivo. This study reported that MWHT induced caspase-3-dependent apoptosis and G2/M cell cycle arrest in NSCLC cells (15). Additionally, it was demonstrated that MWHT combined with GEM markedly inhibited the proliferation and induced the apoptosis of human squamous cell lung carcinoma cells in vitro (16). However, whether autophagy is activated by MWHT in lung cancer cells remains unknown.

Autophagy is the process by which cells encapsulate their own cytoplasmic proteins, intracellular pathogens and damaged organelles to form vesicles in lysosomes under starvation and energy stress conditions $(17,18)$. Autophagy serves a dual role by inhibiting or promoting tumorigenesis and cancer development, and is continually activated in tumor cells following anticancer therapies, such as chemotherapy, radiotherapy and hyperthermia $(19,20)$. Under physiological conditions, reactive oxygen species (ROS) serve an important role in immune response, gene regulation and signaling pathways. Studies have reported that hyperthermia induces autophagy and changes in the intracellular ROS content $(21,22)$. Furthermore, ROS produced by hyperthermia not only participate in the physiological process of cell proliferation, differentiation and apoptosis $(23,24)$, but can also be used as signaling molecules participating in the activation of cell autophagy. The autophagic process is often accompanied by changes in ROS content. However, to the best of our knowledge, the association between ROS and autophagy in MWHT combined with GEM treatment has not been reported in squamous cell lung carcinoma.

In the present study, the effectiveness of MWHT in combination with GEM treatment in human squamous cell lung carcinoma cells was investigated, and the underlying mechanism was examined.

\section{Materials and methods}

Cells and cell cultures. The human squamous cell lung carcinoma cell lines NCI-H1703 and NCI-H2170 were purchased from the American Type Culture Collection (Manassas, VA, USA). Cells were cultured in RPMI-1640 medium supplemented with $10 \%$ fetal bovine serum (FBS; Gibco; Thermo Fisher Scientific, Inc., Waltham, MA, USA) and $1 \%$ penicillin/streptomycin at $37^{\circ} \mathrm{C}$ in an atmosphere containing $5 \% \mathrm{CO}_{2}$.
Treatment of cells with MWHT and GEM. According to the experimental method applied in a previous study (16), NCI-H1703 and NCI-H2170 cell suspensions (1x10 4 cells/well) were seeded into 96-well plates overnight. Cells were then divided into four experimental groups and treated as follows: Control(CON) group, which was not treated; $\mathrm{MW}$ group, treated with the novel microwave applicator alone with a frequency of $433 \mathrm{MHz}$ [ $\pm 5 \mathrm{KHz}$; patent no. CN-204824903-U (15)] at $42^{\circ} \mathrm{C}$ for $60 \mathrm{~min}$; GEM group, treated with GEM (a duration of $24 \mathrm{~h}$; Lilly France, Neuilly-sur-Seine, France) alone at a dose of $5 \mu \mathrm{mol} / \mathrm{l}$; and $\mathrm{MW}+\mathrm{GEM}$ group, in which cells were exposed to GEM (a duration of $24 \mathrm{~h}$ and a dose of $5 \mu \mathrm{mol} / \mathrm{l}$ ), and then treated with MWHT (performed as mentioned in the MW group) at $42^{\circ} \mathrm{C}$ for $60 \mathrm{~min}$. Following the various treatments, the cells were immediately returned to the cell incubator and incubated at $37^{\circ} \mathrm{C}$ for $24 \mathrm{~h}$ prior to further experiments.

Cell viability assay. The effects of the different treatments on cell viability were determined by the Cell Counting Kit-8 (CCK-8) assay (MedChem Express, Monmouth Junction, NJ, USA) according to the manufacturer's protocol. Briefly, $10 \mu \mathrm{l}$ CCK-8 solution was added to cells ( $1 \times 10^{4}$ cells/well) in 96 -well plates, and then the cells were incubated at $37^{\circ} \mathrm{C}$ for $1-3 \mathrm{~h}$. Subsequently, the cell viability in each group was measured at $450 \mathrm{~nm}$ using a Multiskan Spectrum spectrophotometer (Thermo Fisher Scientific, Inc.).

Cell cycle analysis by flow cytometry. Cells were seeded in 6 -well plates at a density of $1 \times 10^{6}$ cells/well, and then divided into the four experimental groups (CON, MW, GEM and $\mathrm{MW}+\mathrm{GEM}$ ). After $24 \mathrm{~h}$ of treatment, the cells were harvested, washed with phosphate-buffered saline (PBS) and fixed with $70 \%$ ice-cold ethanol at $-20^{\circ} \mathrm{C}$ overnight. The cells were then washed further with PBS and stained using the CycletestPlus DNA Reagent kit (BD Biosciences, San Jose, CA, USA), according to the manufacturer's protocol. The cell cycle distribution was analyzed by a flow cytometer (BD Biosciences).

LysoTracker Red staining. Cells were cultured in 6-well plates at a density of $5 \times 10^{5}$ cells/well and separated into the four experimental groups (CON, MW, GEM and MW + GEM). After $24 \mathrm{~h}$ of treatment, cells from the different groups were collected and incubated with $50 \mathrm{nM}$ LysoTracker Red (Beyotime Institute of Biotechnology, Haimen, China) for $30 \mathrm{~min}$ at $37^{\circ} \mathrm{C}$ in the dark. Samples were then analyzed using a fluorescence microscope (BX61; Olympus Corp., Tokyo, Japan) in order to examine autophagy.

Measurement of intracellular ROS generation. Detection of intracellular ROS production was performed by fluorescent probe 2',7'-dichlorodihydrofluorescein diacetate (DCFH-DA) staining (Beyotime Institute of Biotechnology). Briefly, cells were seeded into 6 -well plates at a density of $5 \times 10^{5}$ cells/well in a volume of $2 \mathrm{ml}$ and divided into the four experimental groups (CON, MW, GEM and MW + GEM). After $24 \mathrm{~h}$ of treatment, the cells were preloaded with $10 \mu \mathrm{M}$ DCFH-DA in FBS-free RPMI-1640 medium for $30 \mathrm{~min}$. Subsequent to washing three times with PBS, the cells were mounted under a fluorescence microscope (BX61) at an excitation wavelength of $488 \mathrm{~nm}$ and emission wavelength of $525 \mathrm{~nm}$. Using Image-Pro 
Plus software (Media Cybernetics, Inc., Rockville, MD, USA), the mean fluorescence intensity of the images was assessed and normalized to obtain relative ratios, which were compared among the experimental groups.

Western blot analysis. NCI-H1703 and NCI-H2170 cells in the logarithmic growth phase were collected and seeded at a density of $5 \times 10^{5}$ cells/well in 6 -well plates. Following treatment according to the four experimental groups (CON, MW, GEM and MW + GEM), the cells were then lysed in ice-cold radioimmunoprecipitation assay lysis buffer for $30 \mathrm{~min}$ and then centrifuged at $20,000 \mathrm{x} \mathrm{g}$ for $10 \mathrm{~min}$ at $4^{\circ} \mathrm{C}$ to obtain the total protein. The protein concentration was determined by the BCA assay (Thermo Fisher Scientific, Inc.) according to the manufacturer's protocol. Equal amounts $(40 \mu \mathrm{g})$ of cell lysates were separated by $8-12 \%$ SDS-PAGE and transferred to a polyvinylidene difluoride membrane (Bio-Rad Laboratories, Inc., Hercules, CA, USA). Subsequent to blocking with $5 \%$ non-fat milk for $1-2 \mathrm{~h}$ at room temperature, the membranes were incubated with specific primary antibodies at $4^{\circ} \mathrm{C}$ overnight. The following antibodies were used: Anti-microtubule-associated protein light chain 3 (LC3; dilution 1:1,000; cat. no. sc-398822; Santa Cruz Biotechnology, Santa Cruz, CA, USA), anti-sequestosome1/p62 (SQSTM1/p62; dilution 1:1,000; cat. no. sc-48402; Santa Cruz Biotechnology), anti-phosphatidylinositol 3-kinase (PI3K; dilution 1:1,000; cat. no. 4249; Cell Signaling Technology, Inc., Danvers, MA, USA), anti-phosphorylated-phosphatidylinositol 3-kinase (p-PI3K; dilution 1:1,000; cat. no. 4228; Cell Signaling Technology, Inc.), anti-protein kinase B (AKT; dilution 1:1,000; cat. no. 2920; Cell Signaling Technology, Inc.), anti-phosphorylated-protein kinase B (p-AKT; dilution 1:1,000; cat. no. 4060; Cell Signaling Technology, Inc.), anti-mammalian target of rapamycin (mTOR; dilution 1:1,000; cat. no. 2983; Cell Signaling Technology, Inc.), anti-phosphorylated-mammalian target of rapamycin (p-mTOR; dilution 1:1,000; cat. no. 5536; Cell Signaling Technology, Inc.), anti-phosphorylated-S6 (pS6; dilution 1:1,000; cat. no. 4858; Cell Signaling Technology, Inc.), anti-ribosomal protein S6 kinase (p70S6k; dilution 1:1,000; cat. no. 2708; Cell Signaling Technology, Inc.) and anti- $\beta$-actin (dilution 1:100; cat. no. sc-47778; Santa Cruz Biotechnology). Next, the membranes were washed three times with Tris-buffered saline and Tween 20, and then incubated with horseradish peroxidase-conjugated goat anti-rabbit/mouse IgG secondary antibodies (anti-rabbit IgG; dilution 1:5,000; cat. no. sc-2357; and anti-mouse IgG; dilution 1:5,000; cat. no. sc-2005; from Santa Cruz Biotechnology) at room temperature for a further 1-2 h. An enhanced chemiluminescence detection reagent (Beyotime Institute of Biotechnology) was used for signal detection, and images were captured with an Odyssey infrared imaging system (LI-COR Biosciences, Lincoln, NE, USA). The relative expression level of the total protein is represented by the ratio of the gray value of the total protein band to the gray value of the $\beta$-actin band of the internal reference. The ratio of the gray value of the phosphorylated protein band to the corresponding gray value of the total protein band indicates the relative expression of the phosphorylated protein (ImageJ Software; v.1.8.0; National Institutes of Health, Bethesda, MD, USA). All experiments were repeated at least three times.
Treatment of cells with $\mathrm{N}$-acetyl cysteine (NAC). Cells were pretreated for $1 \mathrm{~h}$ with $5 \mathrm{mmol} / \mathrm{l}$ NAC (Sigma-Aldrich; Merck KGaA, Darmstadt, Germany), a ROS scavenger, and then treated with MWHT and GEM as described earlier. Then, the CCK-8 experiment and the detection of autophagy-related proteins and PI3K/AKT/mTOR pathway proteins were performed.

Treatment of cells with 3-methyladenine (3-MA). Cells were pretreated for $1 \mathrm{~h}$ with $5 \mathrm{mmol} / \mathrm{l}$ 3-MA (Selleck Chemicals, Houston, TX, USA), a selective PI3K inhibitor, which was dissolved in PBS, followed by treatment with MWHT and GEM as described earlier. Subsequently, DCFH-DA staining was performed to examine generation of cellular ROS after treatment with autophagy inhibitors, while the expression levels of autophagy-associated and PI3K/AKT/mTOR proteins were detected by western blot analysis.

Statistical analysis. The statistical analysis was performed using SPSS (version 17.0; SPSS, Inc., Chicago, IL, USA) and GraphPad Prism software (version 7.00 for Macintosh; GraphPad Software, Inc., La Jolla, CA, USA). The one-way ANOVA followed by Tukey's post hoc test was used for multiple comparisons. The results were considered statistically significant when $\mathrm{P}<0.05$. All analyses represented at least three independent in vitro experiments, and the results are expressed as the mean \pm standard deviation.

\section{Results}

MWHT combined with GEM inhibits cell proliferation and induces G0/G1 arrest in squamous cell lung cancer. Our previous study investigated whether MWHT subsequent to treatment with GEM can synergistically inhibit the proliferation of human squamous lung carcinoma cells in vitro (16). To further elucidate the underlying mechanism, the cells were divided into four groups (CON, MW, GEM and MW + GEM), and a CCK-8 assay was conducted to evaluate cell viability. The results revealed that, compared with the CON group, cell viability significantly decreased in the MW, GEM and MW + GEM groups $(\mathrm{P}<0.001)$ in the two cell lines (Fig. 1A). Compared with the GEM or MW alone groups, the cell viability in the combination group was also significantly decreased $(\mathrm{P}<0.001)$. To verify the causal association of cell proliferation inhibition with cell cycle arrest, the cell cycle distribution was analyzed by flow cytometry. As shown in Fig. 1B and C, MW + GEM treatment induced G0/G1 phase arrest, as the cell population at this phase was significantly increased compared with the other three groups in NCI-H1703 cells $(\mathrm{P}<0.01$ or $\mathrm{P}<0.05)$. By contrast, the percentages of cells in the $\mathrm{S}$ and $\mathrm{G} 2 / \mathrm{M}$ phases were significantly decreased $(\mathrm{P}<0.05$ or $\mathrm{P}<0.01)$ compared with the $\mathrm{CON}$ group. Similar effects were also observed in NCI-H2170 cells. These cell cycle changes may have caused the marked reduction in NCI-H1703 and NCI-H2170 cell proliferation.

MWHT combined with GEM induces autophagy. As autophagy contributes to cell death, the present study then investigated whether MWHT in combination with GEM induces autophagy in lung cancer cells. Autophagy is characterized by 
A
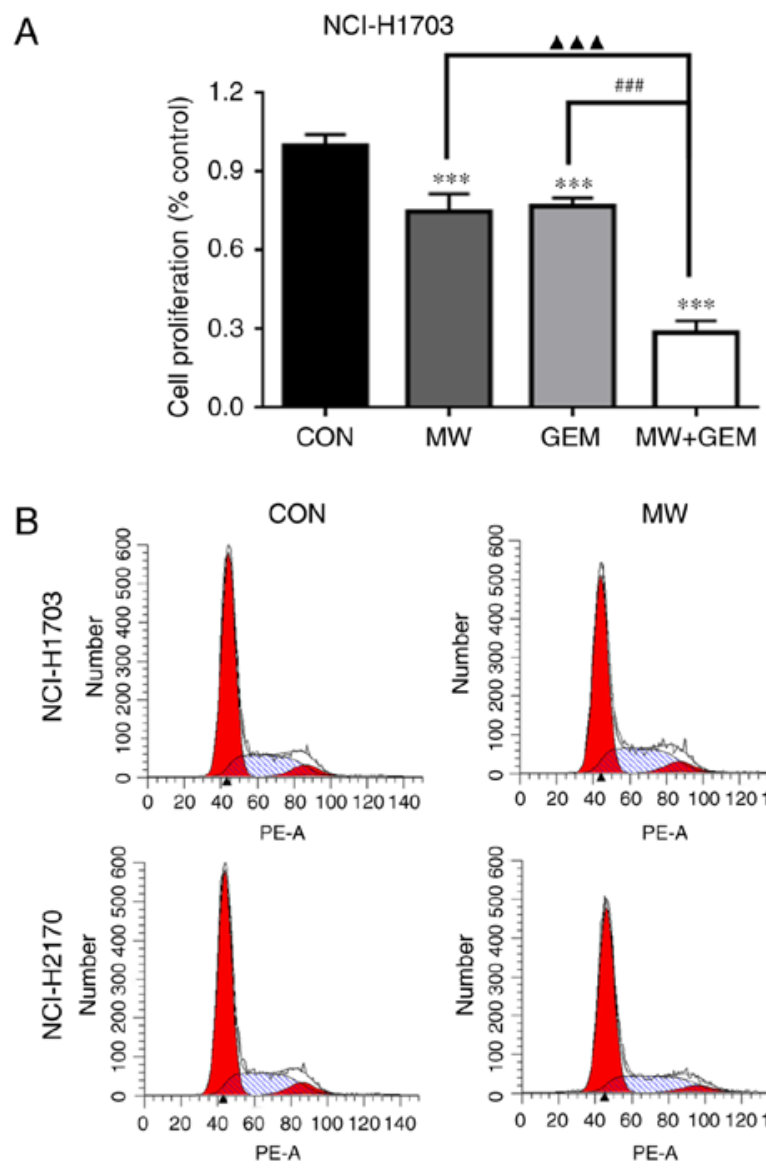

C

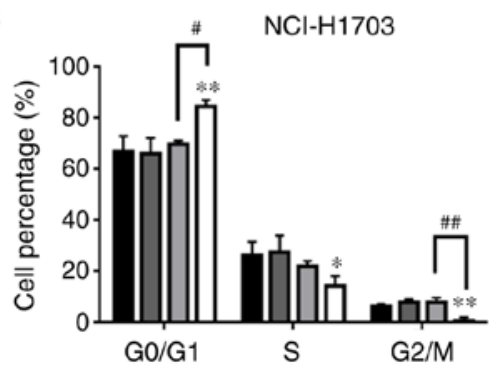

MW
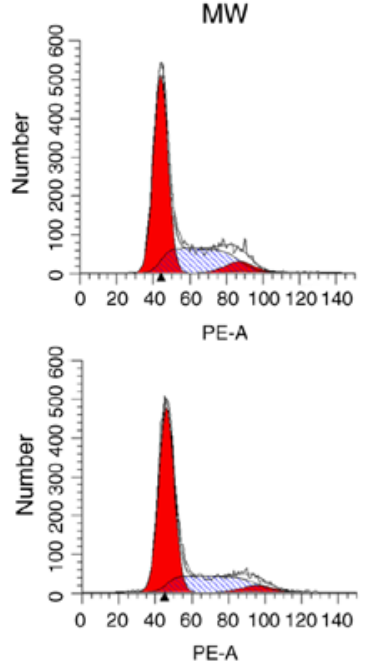

PE-A

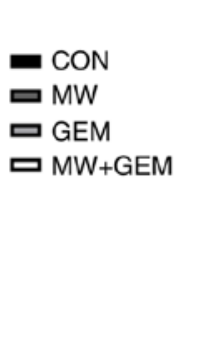

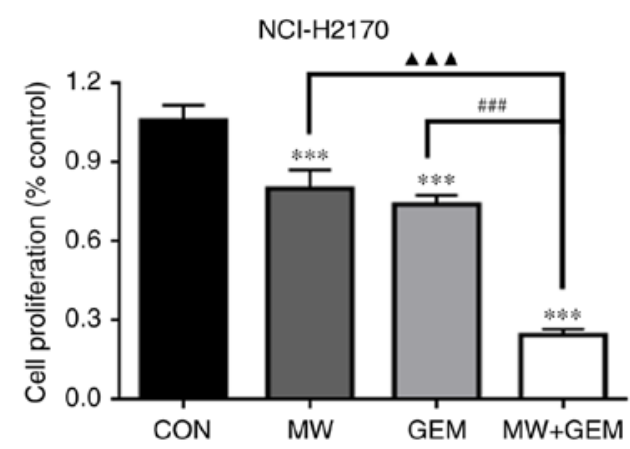
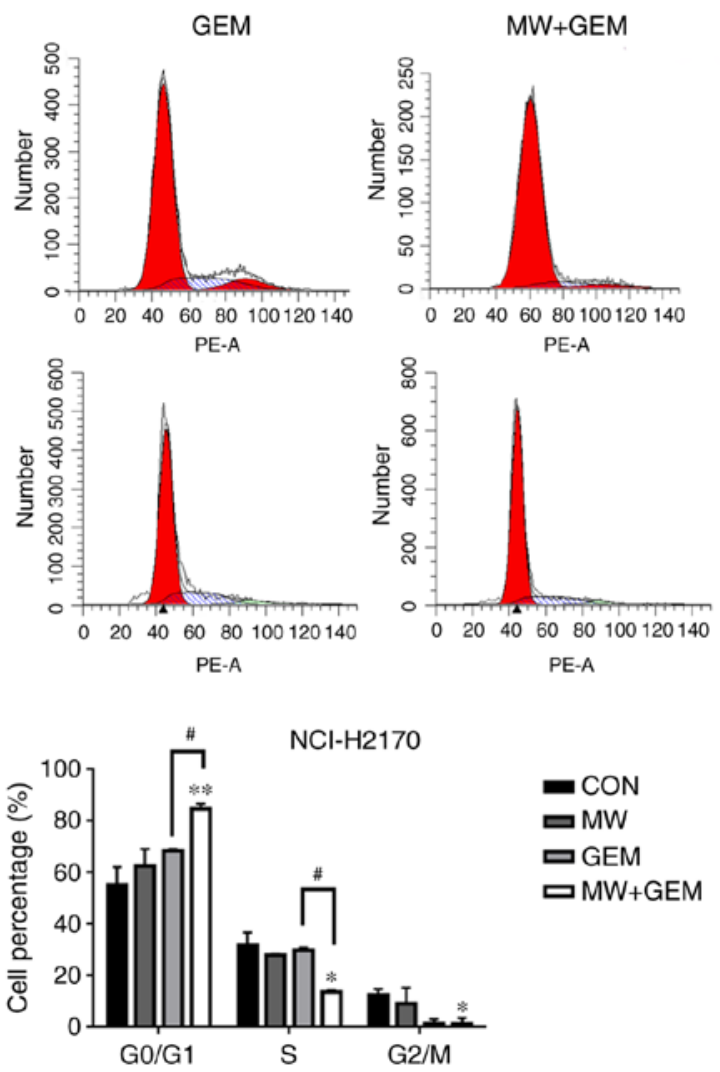

Figure 1. MW + GEM treatment inhibits growth and induces G0/G1 arrest in two squamous cell lung carcinoma cell lines. Cells (1x10 $/$ well) were seeded onto 96-well plate and then divided into four experimental groups. (A) NCI-H1703 and NCI-H2170 cell viability was evaluated by a Cell Counting Kit-8 assay after $24 \mathrm{~h}$ of incubation. (B) Flow cytometry was conducted to assess the cell cycle distribution, and (C) cell percentages in each phase are shown for NCI-H1703 and NCI-H2170 cells. Data are expressed as the mean \pm standard deviation of three independent experiments $(\mathrm{n}=3)$. ${ }^{*} \mathrm{P}<0.05$, ${ }^{* * *} \mathrm{P}<0.01$ and ${ }^{* * *} \mathrm{P}<0.001$, vs. CON group; ${ }^{\#} \mathrm{P}<0.05,{ }^{\# \#} \mathrm{P}<0.01$ and ${ }^{\# \# \#} \mathrm{P}<0.001$, vs. GEM group; ${ }^{\boldsymbol{\Delta} \Delta \boldsymbol{\Delta}} \mathrm{P}<0.001$, vs. MW group. MW, microwave hyperthermia; GEM, gemcitabine; CON, control.

the formation of numerous acidic vesicular organelles, which is correlated with an increased number of autophagosomes and can be detected by LysoTracker Red staining (19,24). LysoTracker Red staining was thus conducted in the present study and was quantified using a fluorescence microscope. The results demonstrated that, compared with GEM or MWHT treatment alone, cell autophagy was significantly increased $(\mathrm{P}<0.001)$ after combined treatment with MWHT and GEM (Fig. 2A). To verify these findings, the expression of several marker proteins of autophagy was further tested by western blotting. The results revealed an increased light chain 3 (LC3)-II/LC3-I ratio and reduced p62 expression in cells receiving combined treatment as compared with those receiving single treatment (Fig. 2B). To further elucidate the mechanism underlying autophagy induction by the combined treatment with MWHT and GEM, 3-MA was used to block autophagy. Consistently, the administration of 3-MA in $\mathrm{MW}+$ GEM cells decreased the ratio of LC3-II/LC3-I protein and increased the expression of p62, as compared with those in cells treated with 3-MA alone (Fig. 2C). Taken together, these findings indicated the crucial role of autophagy in the treatment of squamous cell lung carcinoma with MWHT and GEM.

MWHT combined with GEM increases ROS levels. ROS signaling serves an important role in several biochemical functions, including cell autophagy. Therefore, the production of ROS was detected by DCFH-DA staining and analyzed by fluorescence microscopy. As shown in Fig. 3A and B, the results demonstrated that ROS production increased significantly in the MW + GEM group when compared with 
A

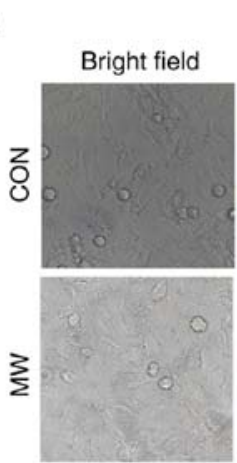

$\mathrm{NCl}-\mathrm{H} 1703$
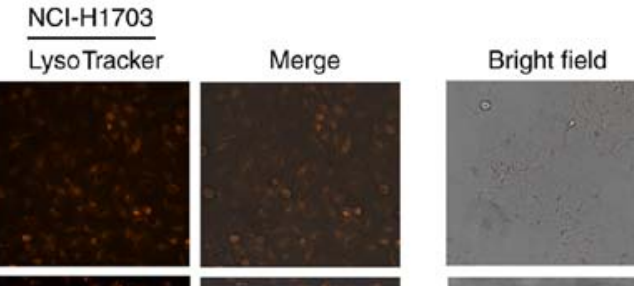

$\mathrm{NCl}-\mathrm{H} 2170$
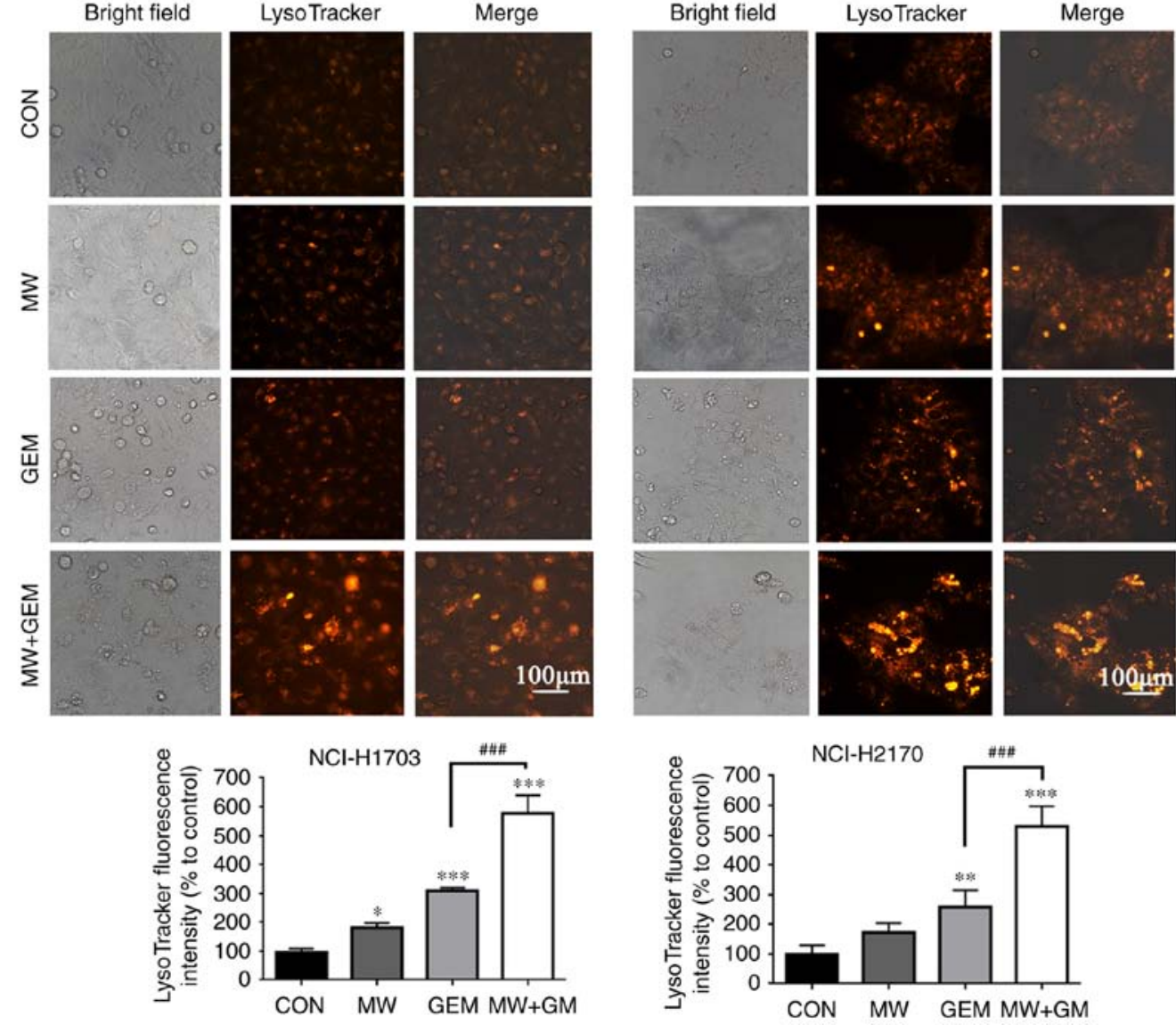

B
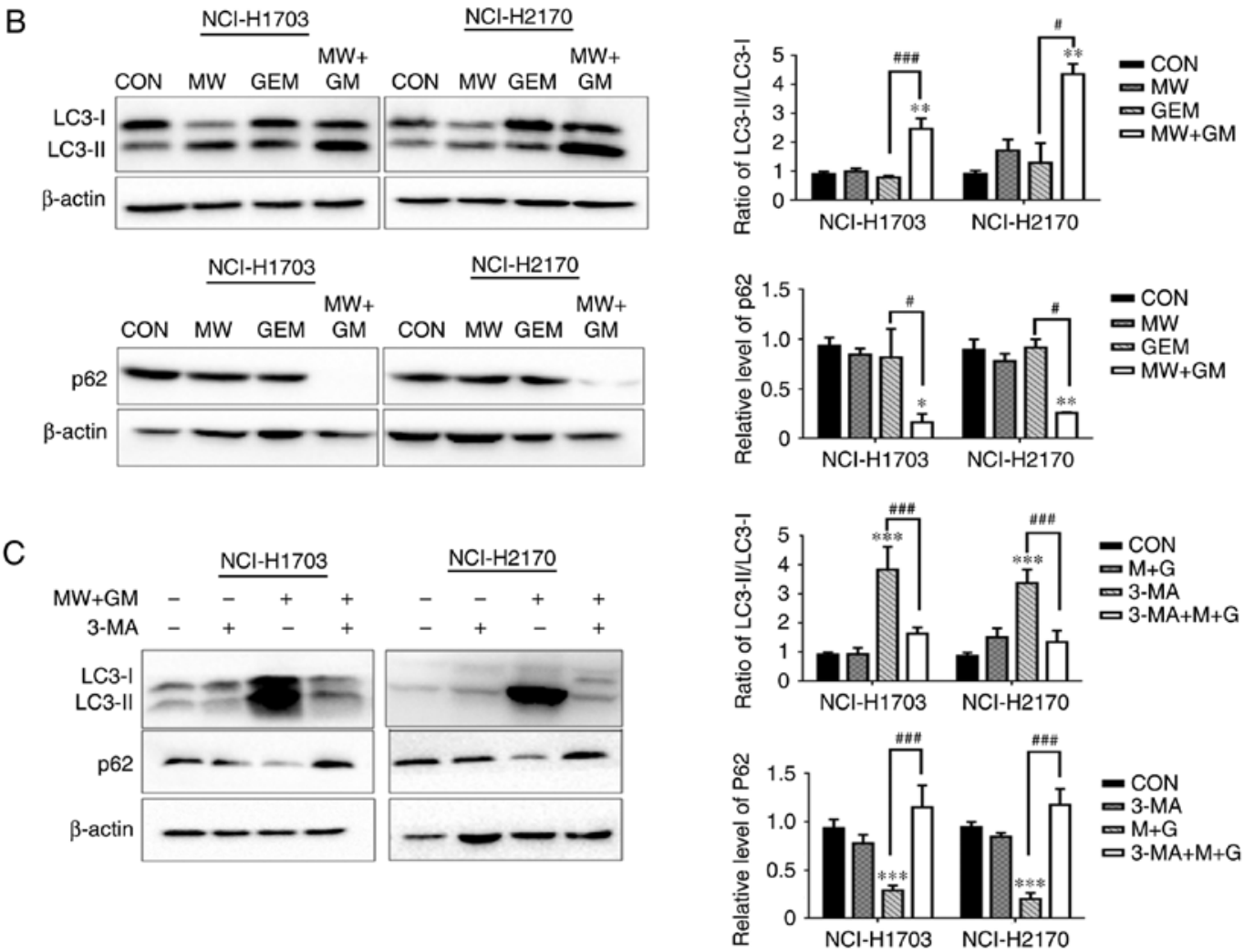

Figure 2. MW + GEM treatment induces autophagy in squamous cell lung carcinoma cells. (A) Representative images of LysoTracker Red staining of cells following treatment with MW + GEM for $24 \mathrm{~h}$. Red color intensity represents acidic vesicular organelles, indicating the autophagosomes (scale bars, $100 \mu \mathrm{m}$ ). (B) Levels of autophagy-associated proteins LC3-II/LC3-I and p62, analyzed by western blotting. (C) Cells were pre-incubated with 3-MA (5 mmol/1) for $1 \mathrm{~h}$, and then treated with MW + GEM for $24 \mathrm{~h}$, followed by western blot analysis of autophagy-associated proteins. The results are presented as the mean \pm standard

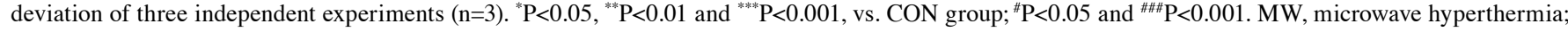
GEM, gemcitabine; 3-MA, 3-methyladenine; LC3, light chain 3; CON, control. 
A
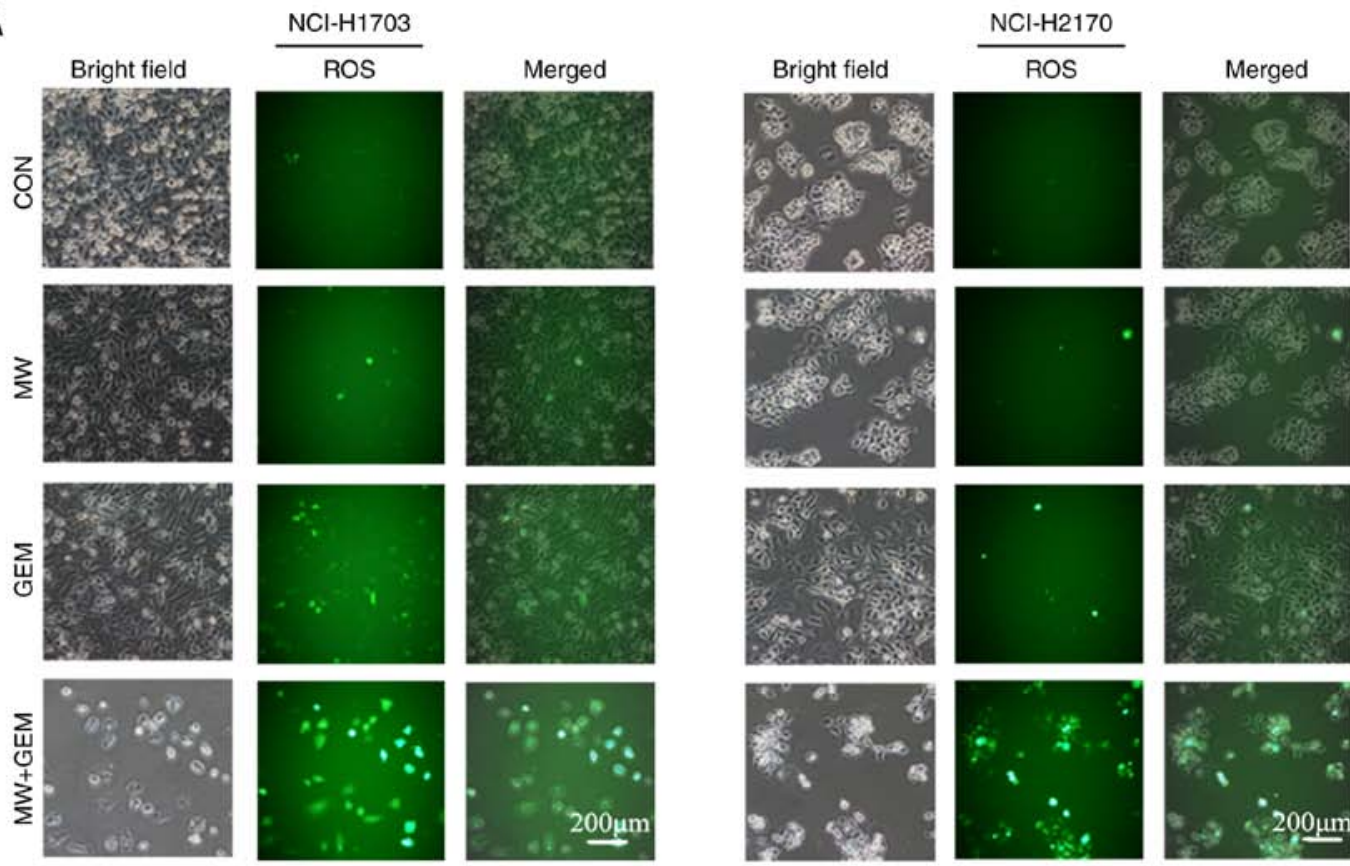

B
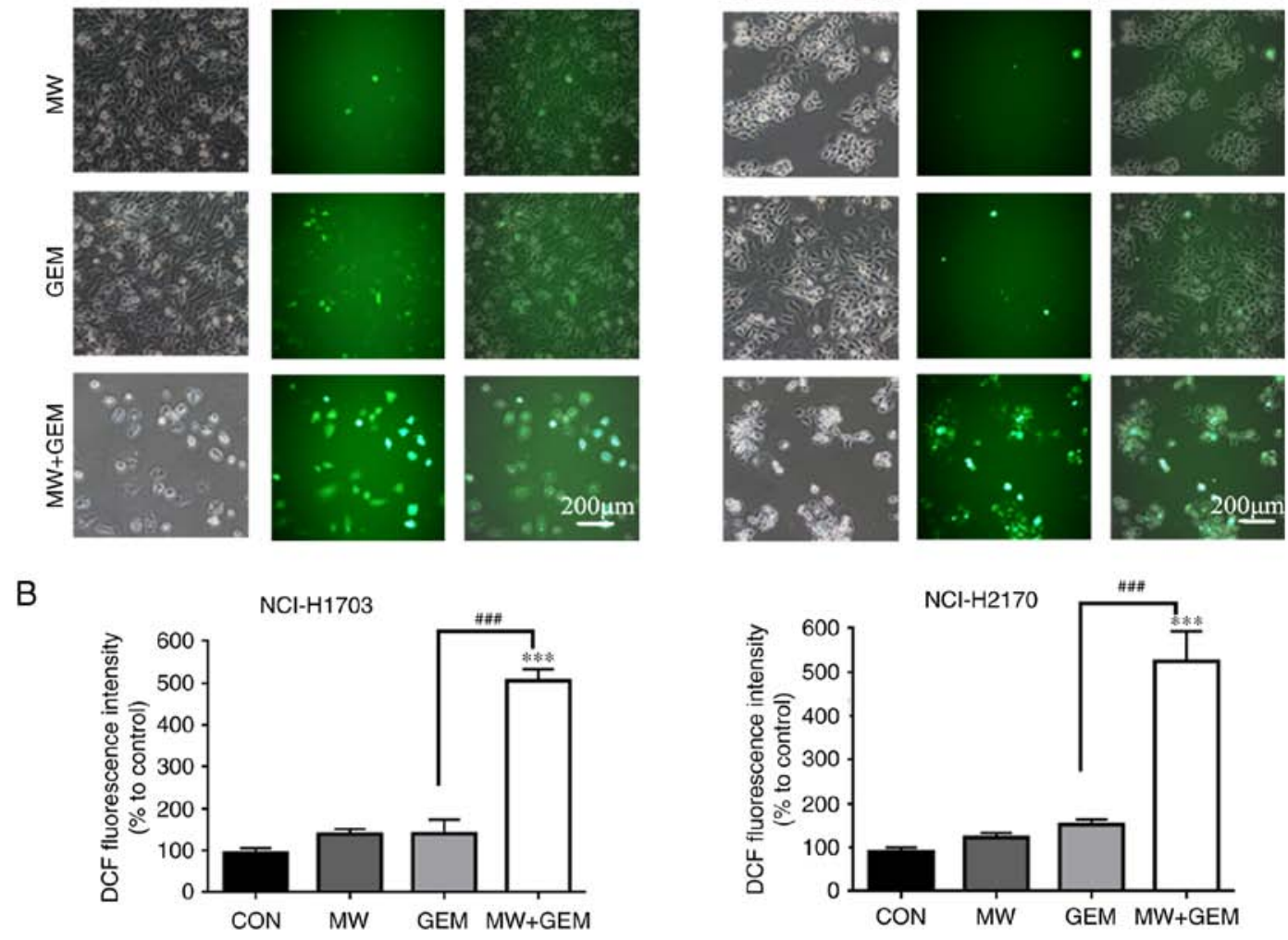

C

$\mathrm{NCl}-\mathrm{H} 1703$
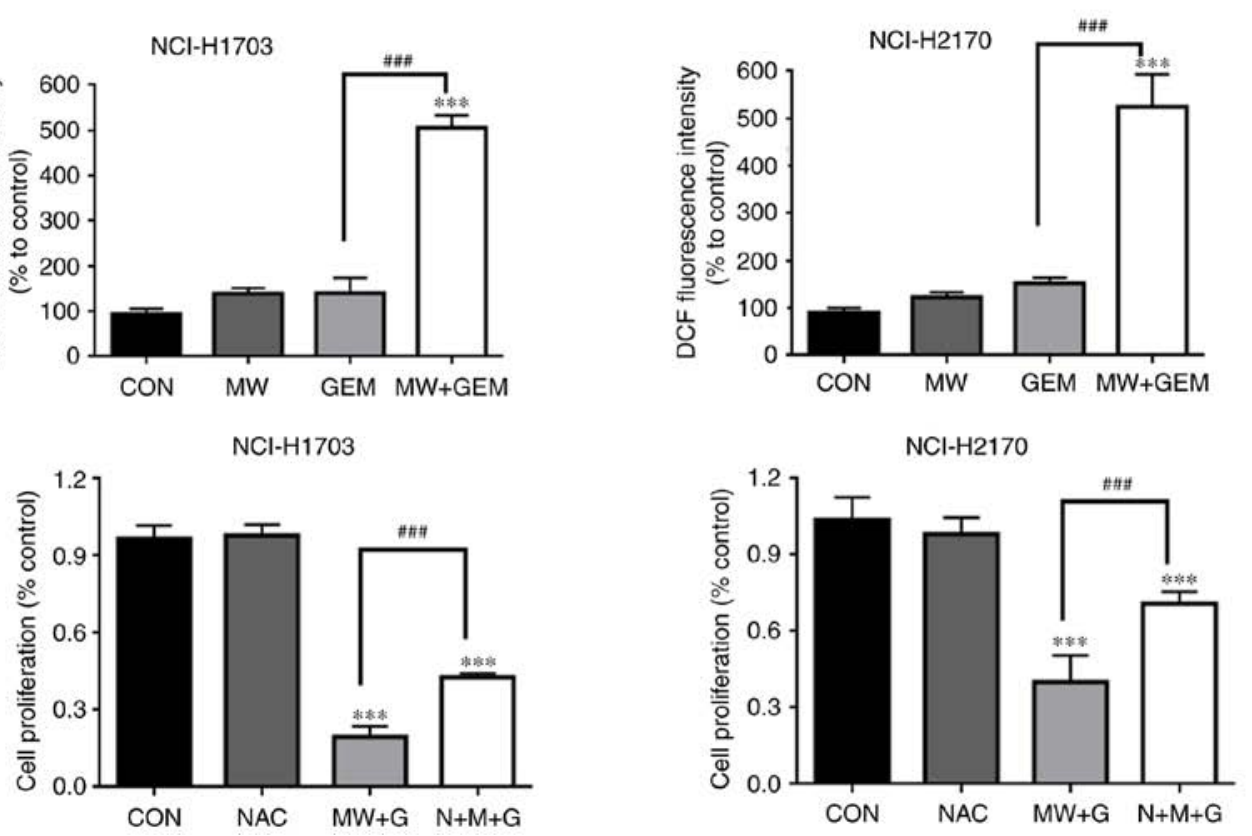

Figure 3. MW + GEM treatment increases ROS levels. Cells were seeded onto 6-well plates at 5x10\%/well, and then exposed to MW and/or GEM treatment for $24 \mathrm{~h}$. Subsequently,cells were preloaded with 2',7'-dichlorodihydrofluorescein diacetate and then mounted under a fluorescent microscope.(A and B) Representative images of DCF fluorescence staining in NCI-H1703 and NCI-H2170 cells (scale bars, $200 \mu \mathrm{m}$ ). Mean fluorescence intensity in NCI-H1703 and NCI-H2170 cells. (C) Cells were preincubated with NAC $(5 \mathrm{mM})$ for $1 \mathrm{~h}$ and then treated with MW + GEM for $24 \mathrm{~h}$. Cell viability was measured by a Cell Counting Kit-8 assay. The results are presented as the mean \pm standard deviation of three independent experiments $(\mathrm{n}=3) .{ }^{* * * *} \mathrm{P}<0.001 \mathrm{vs}$. CON group; ${ }^{\# \# \#} \mathrm{P}<0.001$. MW, microwave hyperthermia; GEM, gemcitabine; ROS, reactive oxygen species; DCF, 2',7'-dichlorofluorescein; CON, control; NAC, N-acetyl cysteine.

the CON group (5.06-fold in NCI-H1703 cells and 5.25-fold in NCI-H2170 cells), while there was no marked increase in ROS production in the MW (1.39-fold in NCI-H1703 cells and 1.23-fold in NCI-H2170 cells) or GEM group alone (1.40-fold in NCI-H1703 cells and 1.39-fold in NCI-H2170 cells). Subsequently, in order to study the effect of ROS accumulation on the antiproliferative potential of MWHT combined with GEM, a CCK-8 assay was performed. As expected, the cell viability in the MW + GEM group was significantly decreased $(\mathrm{P}<0.001)$, whereas pretreatment with NAC markedly prevented cell death $(\mathrm{P}<0.001$; Fig. $3 \mathrm{C})$. These observations further confirmed that MWHT combined with GEM induced NCI-H1703 and NCI-H2170 cell death via the generation of ROS.

MWHT combined with GEM activates the PI3K/AKT/mTOR signaling pathway by inducing ROS production. Several studies have reported that PI3K/AKT/mTOR signaling is involved in the regulation of autophagy. Therefore, the present study investigated the effects of MWHT and GEM on PI3K/AKT/mTOR signaling. As shown in Fig. 4A, compared with the $\mathrm{CON}$ and single treatment groups, the protein 
A

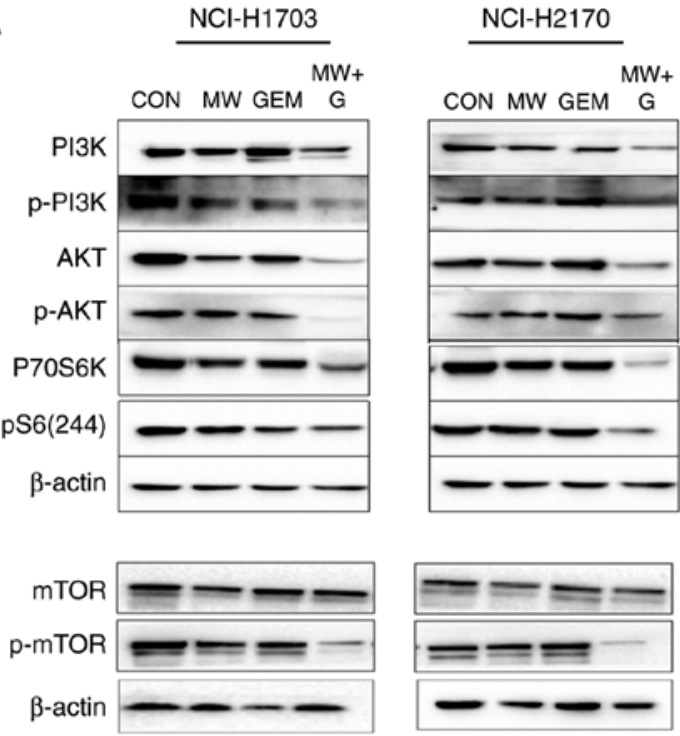

$\mathrm{NCl}-\mathrm{H} 1703$

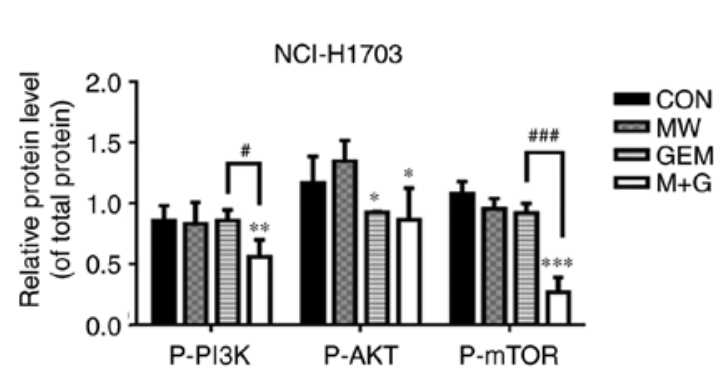

B

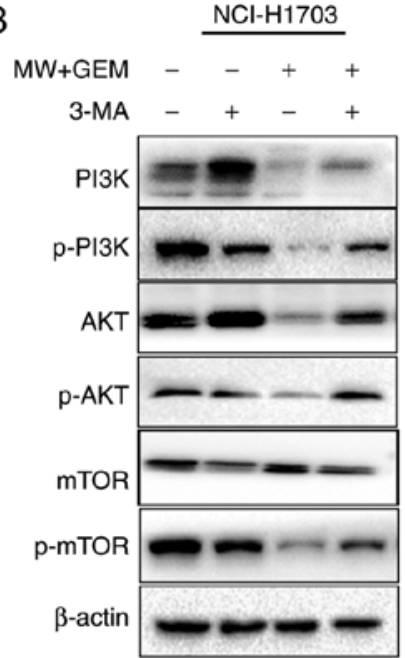

$\mathrm{NCl}-\mathrm{H} 1703$

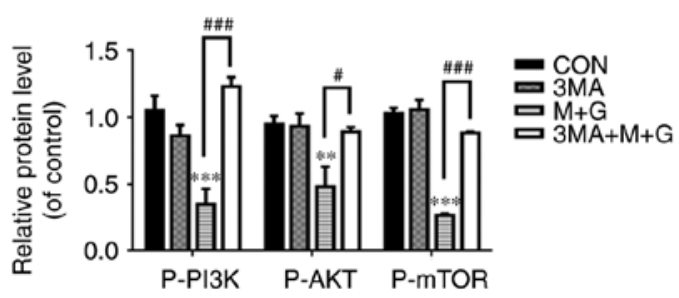

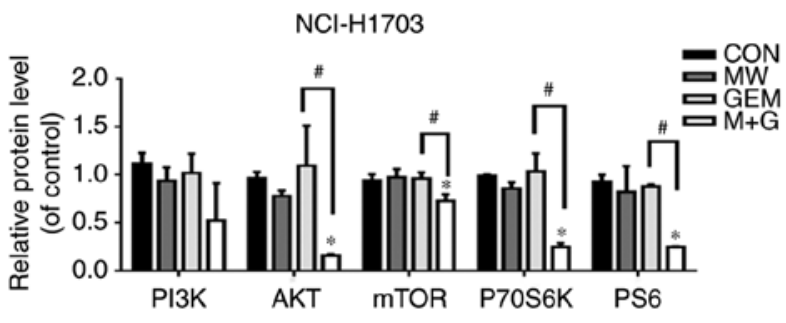

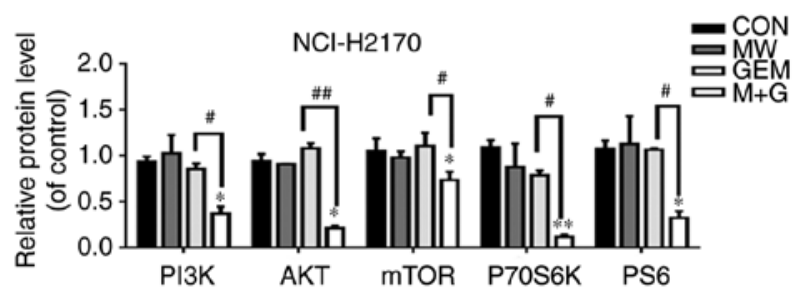

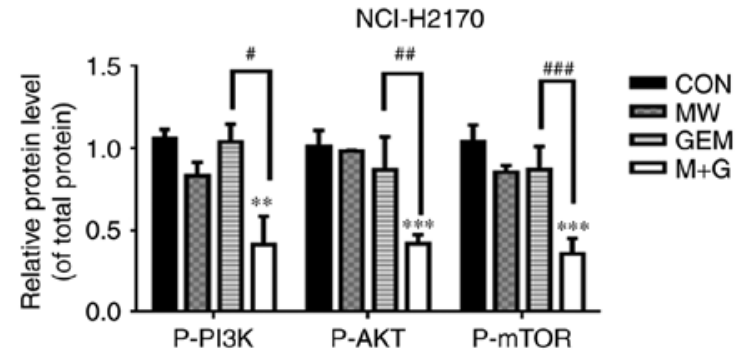
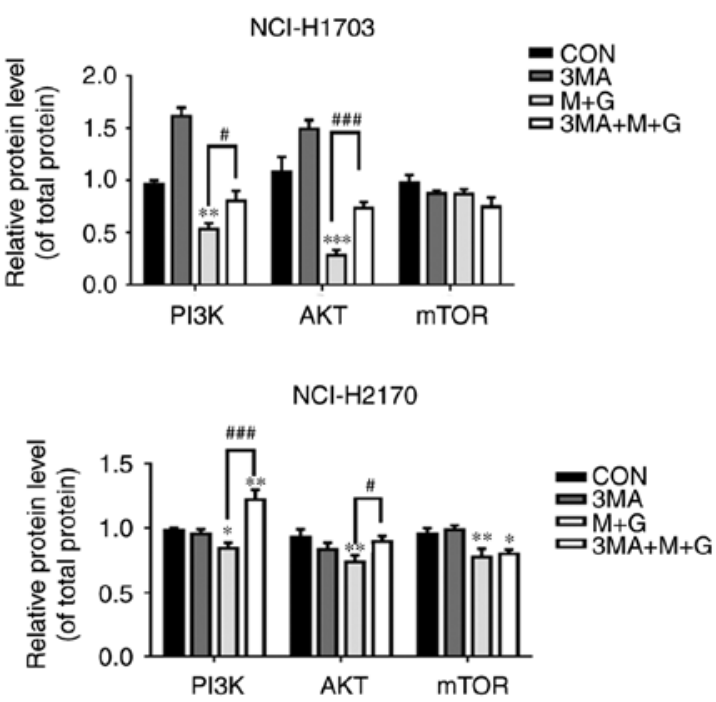

$\mathrm{NCl}-\mathrm{H} 2170$

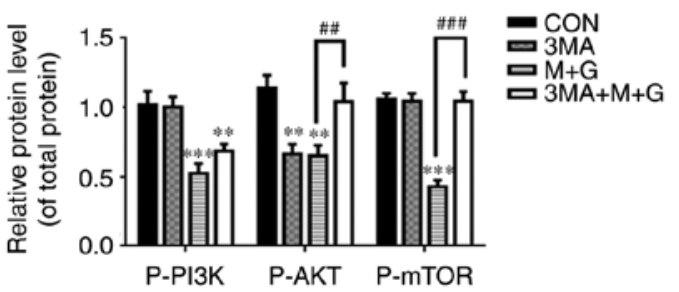

Figure 4. MW + GEM treatment activates the PI3K/Akt/mTOR signaling pathway. (A) Cells were exposed to various treatments for $24 \mathrm{~h}$, and the expression levels of PI3K, p-PI3K, Akt, p-AKT, mTOR, p-mTOR, pS6 and P70S6K proteins were analyzed by western blot assay. (B) Cells were preincubated with 3-MA $(5 \mathrm{mM})$ for $1 \mathrm{~h}$ and then treated with MW + GEM for $24 \mathrm{~h}$, and the expression levels of PI3K, p-PI3K, Akt, p-AKT, mTOR, p-mTOR, pS6 and P70S6K proteins were analyzed by western blot assay. Relative expression levels of PI3K, Akt, mTOR, pS6 and P70S6K, and the phosphorylated proteins p-PI3K, p-Akt and p-mTOR are shown. Each band was quantified using densitometry. The results are presented as mean \pm standard deviation of three independent experiments $(\mathrm{n}=3) .{ }^{*} \mathrm{P}<0.05,{ }^{* *} \mathrm{P}<0.01$ and ${ }^{* * *} \mathrm{P}<0.001$, vs. CON group; ${ }^{\#} \mathrm{P}<0.05,{ }^{\# \#} \mathrm{P}<0.01$ and ${ }^{\# \# \#} \mathrm{P}<0.001$, vs. GEM group. MW, microwave hyperthermia; GEM, gemcitabine; PI3K, phosphoinositide 3-kinase; Akt, protein kinase B; mTOR, mammalian target of rapamycin; P70S6K, p70 S6 kinase; p-, phosphorylated; CON, control. 

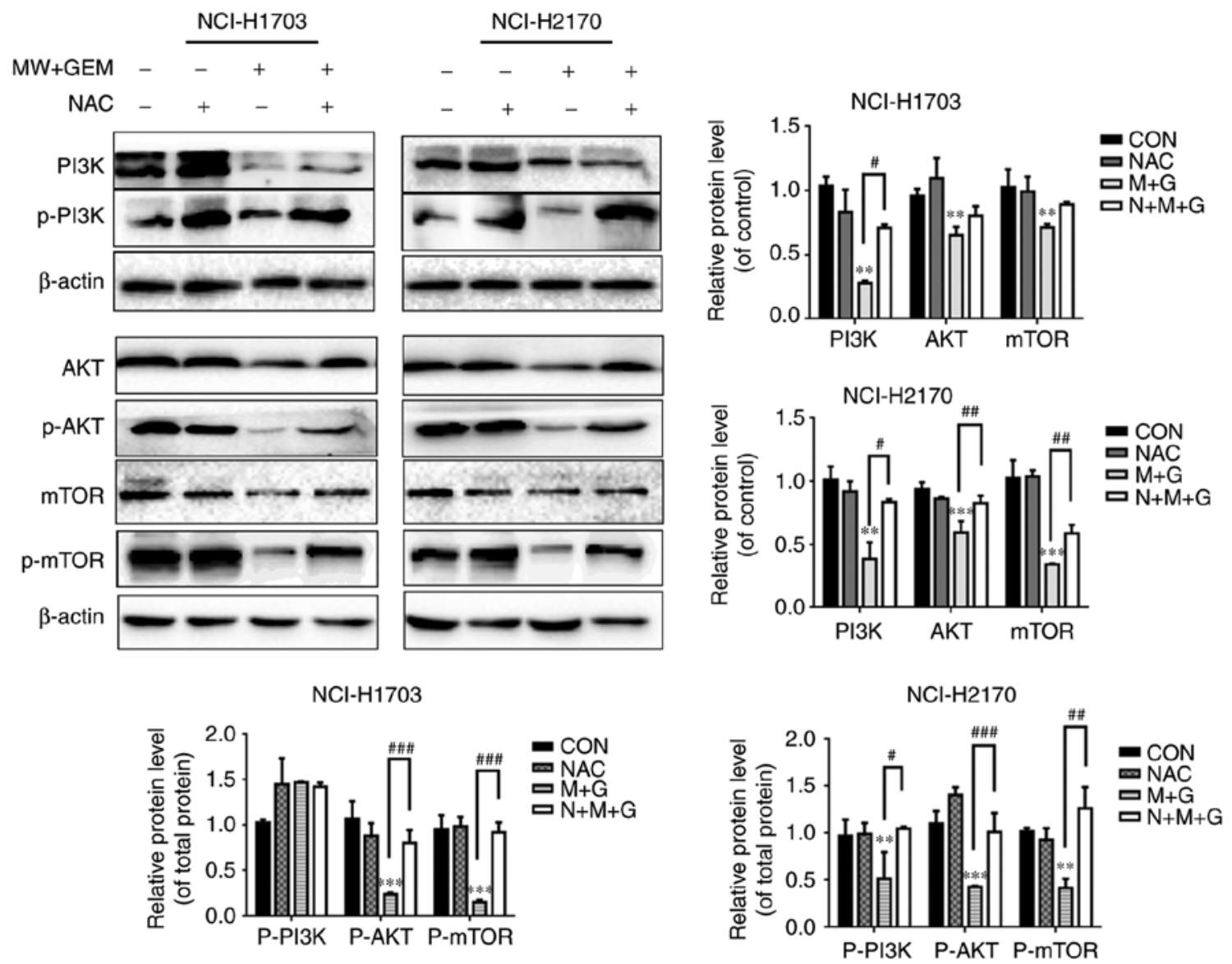

Figure 5. Addition of ROS inhibitions could upregulate the PI3K/Akt/mTOR signaling pathway. Cells were preincubated with NAC (5 mM) for $1 \mathrm{~h}$ and then treated with MW + GEM for $24 \mathrm{~h}$. Protein expression levels of PI3K, p-PI3K, AKT, p-Akt, mTOR and p-mTOR were analyzed by western blot analysis. The results are presented as the mean \pm standard deviation of three independent experiments $(\mathrm{n}=3) .{ }^{* *} \mathrm{P}<0.01$ and ${ }^{* * * *} \mathrm{P}<0.001$, vs. $\mathrm{CON}$ group; ${ }^{\#} \mathrm{P}<0.05,{ }^{\# \#} \mathrm{P}<0.01$ and ${ }^{\# \#} \mathrm{P}<0.001$. MW, microwave hyperthermia; GEM, gemcitabine; PI3K, phosphoinositide 3-kinase; Akt, protein kinase B; mTOR, mammalian target of rapamycin; NAC, $\mathrm{N}$-acetyl cysteine; $\mathrm{CON}$, control.

expression levels of PI3K, phosphorylated (p)-PI3K, AKT, p-AKT, mTOR, p-mTOR, PS6 and p70 S6 kinase (P70S6K) in the MW + GEM group were significantly decreased in the two cell lines $(\mathrm{P}<0.05, \mathrm{P}<0.01$ or $\mathrm{P}<0.001)$. To further examine the association between autophagy and the PI3K/AKT/mTOR signaling pathway, the autophagy inhibitor 3-MA was used. It was revealed that the PI3K/AKT/mTOR pathway was upregulated $(\mathrm{P}<0.05$, or $\mathrm{P}<0.001)$ (Fig. 4B). Taken together, these data indicate that MWHT combined with GEM induce cell autophagy though activation of PI3K/AKT/mTOR signaling. In addition, ROS has been demonstrated to be an inducer for the activation of the PI3K/AKT/mTOR signaling pathway; therefore, the present study further assessed the effect of ROS production on the PI3K/AKT/mTOR pathway using the ROS scavenger NAC. The results demonstrated that pretreatment with NAC, followed by MWHT and GEM treatment, significantly reversed the phosphorylation of PI3K, AKT and mTOR, as compared with $\mathrm{MW}+$ GEM group $(\mathrm{P}<0.01$ or $\mathrm{P}<0.001$; Fig. 5) (35). These changes in the protein expression levels indicated that ROS production was upstream of the $\mathrm{PI} 3 \mathrm{~K} / \mathrm{AKT} / \mathrm{mTOR}$ signaling pathway.

MWHT combined with GEM induces autophagy by inducing ROS production. To elucidate the interplay between ROS and autophagy, the underlying molecular mechanism was further investigated using western blot analysis. Notably, the protein expression levels of p62 were found to be significantly increased following pretreatment with NAC in the MW + GEM group for $24 \mathrm{~h}$, as compared with the group without NAC $(\mathrm{P}<0.001$; Fig. 6A). By contrast, the ratio of the LC3-II/LC3-I protein level was markedly decreased in the NAC pretreated cells, as compared with the MW + GEM group ( $\mathrm{P}<0.001$; Fig. 6A). Furthermore, when the autophagy inhibitor 3-MA was used, no significant change was observed in ROS production (Fig. 6B). Taken together, these results indicate that MWHT in combination with GEM induced autophagy through ROS-mediated $\mathrm{PI} 3 \mathrm{~K} / \mathrm{AKT} / \mathrm{mTOR}$ signaling in the two human squamous cell lung carcinoma cell lines.

\section{Discussion}

The present study investigated the anticancer effects of MWHT combined with GEM on the squamous cell lung carcinoma NCI-H1703 and NCI-H2170 cell lines, and demonstrated that the combined treatment effectively inhibited cancer cell proliferation by inducing cell cycle arrest. Furthermore, the results revealed that the combined treatment predominantly induced autophagic cell death through the inhibition of the ROS-mediated PI3K/AKT/mTOR signaling pathway in squamous cell lung carcinoma. 
A
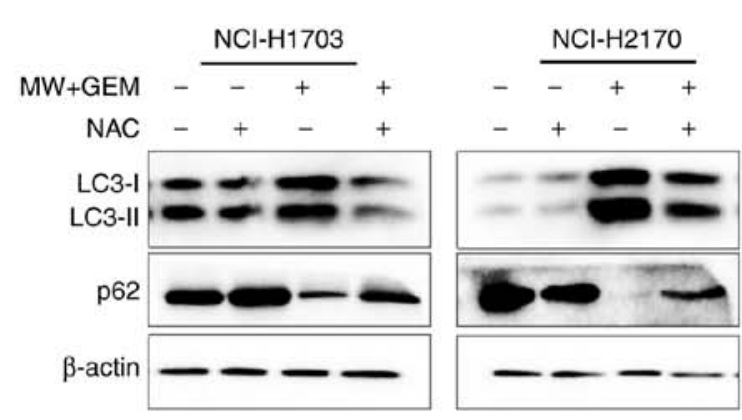

B
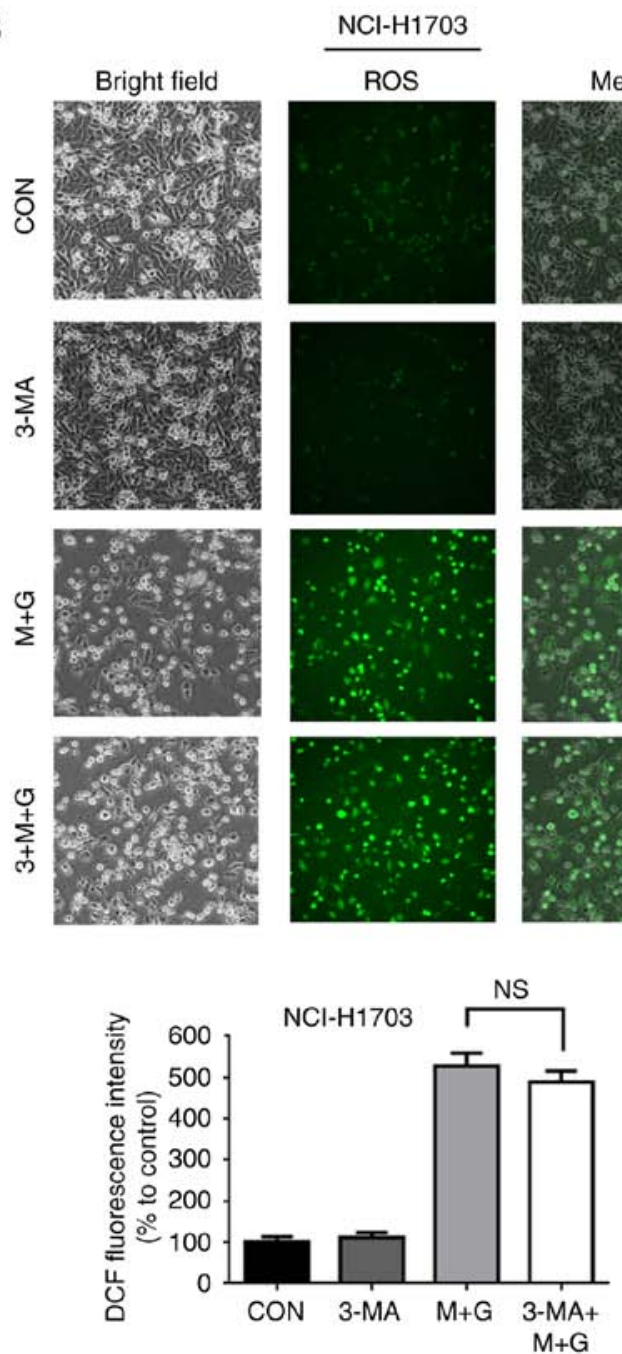
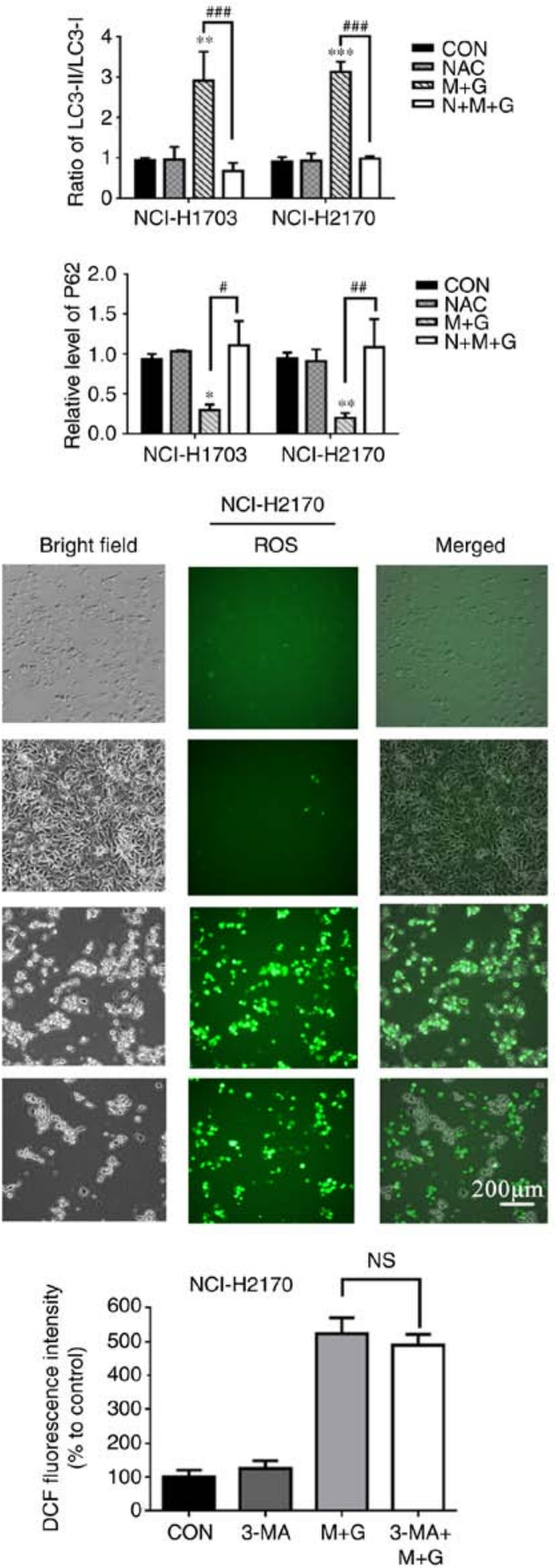

Figure 6. Addition of autophagy inhibitions could upregulate the PI3K/Akt/mTOR signaling pathway. MW + GEM treatment induces autophagy by inducing ROS production. (A) Cells were preincubated with NAC $(5 \mathrm{mM})$ for $1 \mathrm{~h}$ and then treated with MW + GEM for $24 \mathrm{~h}$. Protein expression levels of LC3-II/LC3-I and p62 were analyzed by western blot analysis. (B) Cells were preincubated with 3-MA (5 mM) for $1 \mathrm{~h}$ and then treated with MW + GEM for $24 \mathrm{~h}$. Representative images of DCF fluorescence staining in NCI-H1703 and NCI-H2170 cells (scale bars, $200 \mu \mathrm{m}$ ). The results are presented as the mean \pm standard deviation of three independent experiments $(\mathrm{n}=3)$. ${ }^{*} \mathrm{P}<0.05,{ }^{* *} \mathrm{P}<0.01$ and ${ }^{* * * *} \mathrm{P}<0.001$, vs. CON group; ${ }^{\#} \mathrm{P}<0.05,{ }^{\# \#} \mathrm{P}<0.01$ and ${ }^{\# \# \#} \mathrm{P}<0.001$. MW, microwave hyperthermia; GEM, gemcitabine; NAC, N-acetyl cysteine; LC3, light chain 3; p-, phosphorylated; 3-MA, 3-methyladenine; ROS, reactive oxygen species; DCF, 2',7'-dichlorofluorescein; p-, phosphorylated; CON, control; NS, not significant.

The cell cycle, consisting of the G0/G1, S and G2/M phases, regulates a number of cell processes, including proliferation, differentiation and apoptosis. The loss of cell cycle control, particularly loss of the G1/S and G2/M checkpoints, is closely associated with tumorigenesis. It has previously been demonstrated that GEM can cause G1/S arrest in tumor cells (25), which is consistent with the experimental results of the present study. By contrast, hyperthermia has been reported 
to cause $\mathrm{G} 2 / \mathrm{M}$ phase arrest $(15,26)$; however, the combined effect of GEM and hyperthermia is complex, and may involve G2/M phase block (27), as well as G0/G1 phase block (28). The experimental results presented in the present study demonstrated that the number of cells in the G0/G1 phase increased significantly upon co-treatment with MWHT and GEM, which is in accordance with previous findings (28), indicating that the combined effect of MWHT and GEM causes G0/G1 phase arrest in squamous cell lung carcinoma.

A growing body of evidence indicates that autophagy closely regulates tumor response by protecting cell survival or contributing to cell death. Autophagy is a programmed intracellular degradation process, during which the cells are transported to the lysosomes and digested to meet metabolic needs, organelle turnover and maintenance of cell homeostasis (17). The process of autophagy is mainly divided into five stages, as follows: i) Phagophore formation; ii) Atg5-Atg12 conjugation; iii) LC3 processing; iv) autophagosome formation; and v) autolysosome formation. The increase of autolysosomes, the conversion of LC3-I to LC3-II and the downregulation of the $\mathrm{p} 62$ protein are often used as markers of autophagy (18). In the present study, it was demonstrated that MWHT combined with GEM increased the number of autolysosomes, upregulated LC3-II levels and downregulated the expression of the p62 protein compared with the control group. These results indicate that thermal inhibition of the proliferation of squamous cell lung carcinoma cells may be closely associated with the induction of autophagy.

ROS is crucial for the regulation of cell death and survival in cancer. It has been reported that ROS can induce the dissociation of autophagy molecules Beclin 1 and B-cell lymphoma-2, thus activating the Beclin 1-induced autophagic pathway, inhibiting mTOR and increasing the expression of LC3-II, thereby initiating autophagy-associated pathways to induce cell death (29). In the present study, MWHT combined with GEM treatment resulted in a significant increase in ROS generation, while pretreatment with the ROS inhibitor NAC markedly reversed the inhibition of cell proliferation and autophagy induced by MWHT and GEM. In addition, compared with cells only treated with MWHT and GEM, the ROS level was not significantly altered when cells were co-treated with MWHT + GEM and 3-MA, which was consistent with the results of the Zhang et al (30). The present study results thus indicated that ROS acts upstream of autophagy in squamous cell lung carcinoma.

Previous studies have reported that several key molecules and signaling pathways may regulate autophagy $(31,32)$. Among them, the PI3K/AKT/mTOR signaling pathway has been extensively investigated. The role of this pathway is pivotal in the regulation of cell proliferation, differentiation and survival under normal physiological conditions, as well as during pathophysiological processes $(33,34)$. In the present study, it was observed that treatment of lung cancer cells with MWHT and GEM decreased the levels of phosphorylated PI3K, AKT and mTOR, suggesting that autophagy was induced via suppression of PI3K/AKT/mTOR signaling in these cells. Furthermore, intracellular ROS production reportedly serves a key role in PI3K/AKT/mTOR inactivation and autophagy (35). In the present study, autophagy and LC3 expression were significantly restored by a ROS scavenger,
NAC, in NCI-H1703 and NCI-H2170 cells. Furthermore, pretreatment with NAC nearly attenuated the phosphorylation of PI3K, AKT and mTOR. Taken together, these data indicated that MWHT combined with GEM induced cell autophagy though the activation of ROS-mediated PI3K/AKT/mTOR signaling.

In conclusion, to the best of our knowledge, the present study results are the first to demonstrate that treatment with MWHT combined with GEM induces G0/G1 cell cycle arrest and causes cell autophagy that is regulated via ROS-mediated $\mathrm{PI} 3 \mathrm{~K} / \mathrm{AKT} / \mathrm{mTOR}$ signaling. These results contribute to the understanding of the biological effects of thermo-chemotherapy on cancer cells, and indicate that the combination of MWHT and GEM is a promising anticancer therapy in human squamous cell lung carcinoma. However, it is important to investigate the interplay between apoptosis and autophagy, and determine whether their genetic and pharmacological manipulation may affect the efficacy of thermal anticancer treatments. In addition, further research on animal models is required in the future.

\section{Acknowledgements}

Not applicable.

\section{Funding}

The present study was supported by a grant from the National Natural Science Foundation (no. U1504822). The funder had no part in the study design, data collection and analysis, decision to publish, or preparation of the manuscript.

\section{Availability of data and materials}

The datasets used and/or analyzed during the present study are available from the corresponding authors on reasonable request.

\section{Authors' contributions}

YangY, SLM and DKY designed the experiments; SLM and DKY were involved in project administration; YangY, SLM and DKY wrote and edited the manuscript; YangY, CLY, ZJZ, XXZ, TSL and YaY performed the experiments and analyzed the data. All authors read and approved the manuscript and agree to be accountable for all aspects of the research in ensuring that the accuracy or integrity of any part of the work are appropriately investigated and resolved.

\section{Ethics approval and consent to participate}

Not applicable.

\section{Patient consent for publication}

Not applicable.

\section{Competing interests}

The authors declare that they have no competing interests. 


\section{References}

1. Siegel RL, Miller KD and Jemal A: Cancer statistics, 2015. CA Cancer J Clin 65: 5-29, 2015.

2. Heist RS, Mino-Kenudson M, Sequist LV, Tammireddy S, Morrissey L, Christiani DC, Engelman JA and Iafrate AJ FGFR1 amplification in squamous cell carcinoma of the lung. J Thorac Oncol 7: 1775-1780, 2012.

3. Derman BA, Mileham KF, Bonomi PD, Batus M and Fidler MJ: Treatment of advanced squamous cell carcinoma of the lung: A review. Transl Lung Cancer Res 4: 524-532, 2015.

4. Sun Y, Wu YL, Zhou CC, Zhang L, Zhang L, Liu XY, Yu SY, Jiang GL, Li K, Qin SK, et al: Second-line pemetrexed versus docetaxel in Chinese patients with locally advanced or metastatic non-small cell lung cancer: A randomized, open-label study. Lung Cancer 79: 143-150, 2013.

5. Palumbo R, Sottotetti F, Trifirò G, Piazza E, Ferzi A, Gambaro A Spinapolice EG, Pozzi E, Tagliaferri B, Teragni C, et al: Nanoparticle albumin-bound paclitaxel (nab-paclitaxel) as second-line chemotherapy in HER2-negative, taxane-pretreated metastatic breast cancer patients: Prospective evaluation of activity, safety, and quality of life. Drug Des Devel Ther 9: 2189-2199, 2015.

6. Duan J, Wang Z, Bai H, An T, Zhuo M, Wu M, Wang Y, Yang L and Wang J: Epidermal growth factor receptor variant III mutation in Chinese patients with squamous cell cancer of the lung. Thorac Cancer 6: 319-326, 2015.

7. Hurwitz M and Stauffer P: Hyperthermia, radiation and chemotherapy: The role of heat in multidisciplinary cancer care. Semin Oncol 41: 714-729, 2014.

8. Salahi S, Maccarini PF, Rodrigues DB, Etienne W, Landon CD, Inman BA, Dewhirst MW and Stauffer PR: Miniature microwave applicator for murine bladder hyperthermia studies. Int J Hyperthermia 28: 456-465, 2012.

9. Asano M, Tanaka S, Sakaguchi M, Matsumura H, Yamaguchi T, Fujita Y and Tabuse K: Normothermic microwave irradiation induces death of HL-60 cells through Heat-independent apoptosis. Sci Rep 7: 11406, 2017.

10. Li C, Li C, Ge H, Liang M, Ma G, Ling L, Pan H, Gong H, Xie H, Ding Q, et al: Technical analysis of US imaging for precise microwave ablation for benign breast tumours. Int J Hyperthermia 34: $1179-1185,2018$

11. Han JB, Kong FW, Ding H, Zhang YF, Liu JM, Wei Q, Hu L, Zhao L, Xu CJ and Yi YX: Hepatectomy combined with microwave ablation of the spleen for treatment of hepatocellular carcinoma complicated with splenomegaly: A retrospective study. Mol Clin Oncol 6: 204-208, 2017.

12. Kouloulias V, Triantopoulou S, Vrouvas J, Gennatas K, Oozounoglou N, Kouvaris J, Karaiskos P, Aggelakis P, Antypas C, Zygogianni A, et al: Combined chemoradiotherapy with local microwave hyperthermia for treatment of T3N0 laryngeal carcinoma: A retrospective study with long-term follow-up. Acta Otorhinolaryngol Ital 34: 167-173, 2014.

13. Othman T, Goto S, Lee JB, Taimura A, Matsumoto T and Kosaka M: Hyperthermic enhancement of the apoptotic and antiproliferative activities of paclitaxel. Pharmacology 62 : 208-212, 2001

14. Adachi S, Kokura S, Okayama T, Ishikawa T, Takagi T, Handa O, Naito Y and Yoshikawa T: Effect of hyperthermia combined with gemcitabine on apoptotic cell death in cultured human pancreatic cancer cell lines. Int J Hyperthermia 25: 210-219, 2009.

15. Zhao YY, Wu Q, Wu ZB, Zhang JJ, Zhu LC, Yang Y, Ma SL and Zhang SR: Microwave hyperthermia promotes caspase3 -dependent apoptosis and induces $\mathrm{G}_{2} / \mathrm{M}$ checkpoint arrest via the ATM pathway in non-small cell lung cancer cells. Int J Oncol 53: 539-550, 2018

16. Yang Y, Zhao Y, Ma S and Yang D: Microwave hyperthermia combined with gemcitabine inhibits proliferation and induces apoptosis of human lung squamous carcinoma cells. Zhongguo Fei Ai Za Zhi 21: 805-814, 2018 (In Chinese).

17. White EJ, Martin V, Liu JL, Klein SR,Piya S, Gomez-Manzano C, Fueyo $\mathrm{J}$ and Jiang H: Autophagy regulation in cancer development and therapy. Am J Cancer Res 1: 362-372, 2011.
18. Rosenfeldt MT and Ryan KM: The multiple roles of autophagy in cancer. Carcinogenesis 32: 955-963, 2011.

19. Wang H, Zhang T, Sun W, Wang Z, Zuo D, Zhou Z, Li S, Xu J, Yin F, Hua Y, et al: Erianin induces G2/M-phase arrest, apoptosis, and autophagy via the ROS/JNK signaling pathway in human osteosarcoma cells in vitro and in vivo. Cell Death Dis 7: e2247, 2016.

20. Ba MC, Long H, Wang S, Wu YB, Zhang BH, Yan ZF, Yu FH and Cui SZ: Hyperthermia enhances radiosensitivity of colorectal cancer cells through ROS inducing autophagic cell death. J Cell Biochem 119: 3763-3774, 2018.

21. Chen F, Wang CC, Kim E and Harrison LE: Hyperthermia in combination with oxidative stress induces autophagic cell death in HT-29 colon cancer cells. Cell Biol Int 32: 715-723, 2008.

22. Wang Z, Cai F, Chen X, Luo M, Hu L and Lu Y: The role of mitochondria-derived reactive oxygen species in hyperthermia-induced platelet apoptosis. PLoS One 8: e75044, 2013.

23. Hou CH, Lin FL, Hou SM and Liu JF: Hyperthermia induces apoptosis through endoplasmic reticulum and reactive oxygen species in human osteosarcoma cells. Int J Mol Sci 15: 17380-17395, 2014

24. Klionsky DJ, Abdalla FC, Abeliovich H, Abraham RT, Acevedo-Arozena A, Adeli K, Agholme L, Agnello M, Agostinis P, Aguirre-Ghiso JA, et al: Guidelines for the use and interpretation of assays for monitoring autophagy. Autophagy 8: 445-544, 2012.

25. Martinotti S, Ranzato E, Parodi M, Vitale M and Burlando B: Combination of ascorbate/epigallocatechin-3-gallate/gemcitabine synergistically induces cell cycle deregulation and apoptosis in mesothelioma cells. Toxicol Appl Pharmacol 274: 35-41,2014.

26. Furusawa Y, Iizumi T, Fujiwara Y, Zhao QL, Tabuchi Y, Nomura $T$ and Kondo T: Inhibition of checkpoint kinase 1 abrogates $\mathrm{G} 2 / \mathrm{M}$ checkpoint activation and promotes apoptosis under heat stress. Apoptosis 17: 102-112, 2012.

27. Michalakis J, Georgatos SD, Romanos J, Koutala H, Georgoulias V, Tsiftsis D and Theodoropoulos PA: Micromolar taxol, with or without hyperthermia induces mitotic catastrophe and cell necrosis in HeLa cells. Cancer Chemother Pharmacol 56: 615-622, 2005 .

28. Haveman J, Rietbroek RC, Geerdink A, Van Rijn J and Bakker PJ: Effect of hyperthermia on the cytotoxicity of 2',2'-difluorodeoxycytidine (gemcitabine) in cultured SW1573 cells. Int J Cancer 62: 627-630, 1995.

29. Ba MC, Long H, Cui SZ, Gong YF, Yan ZF, Wang S and Wu YB: Mild hyperthermia enhances sensitivity of gastric cancer cells to chemotherapy through reactive oxygen species-induced autophagic death. Tumor Biol 39: 1010428317711952, 2017.

30. Zhang L, Wang H, Xu J, Zhu J and Ding K: Inhibition of cathepsin $\mathrm{S}$ induces autophagy and apoptosis in human glioblastoma cell lines through ROS-mediated PI3K/AKT/mTOR/p70S6K and JNK signaling pathways. Toxico Lett 228: 248-259, 2014.

31. Dewaele M, Maes H and Agostinis P: ROS-mediated mechanisms of autophagy stimulation and their relevance in cancer therapy. Autophagy 6: 838-854, 2010.

32. Xiong Y, Yepuri G, Forbiteh M, Yu Y, Montani JP, Yang Z and Ming XF: ARG2 impairs endothelial autophagy through regulation of MTOR and PRKAA/AMPK signaling in advanced atherosclerosis. Autophagy 10: 2223-2238, 2014.

33. Zhang Q, Zhu H, Xu X, Li L, Tan H and Cai X: Inactivated Sendai virus induces apoptosis and autophagy via the $\mathrm{PI} 3 \mathrm{~K} / \mathrm{Akt} / \mathrm{mTOR} / \mathrm{p} 70 \mathrm{~S} 6 \mathrm{~K}$ pathway in human nonsmall cell lung cancer cells. Biochem Biophys Res Commun 465: 64-70, 2015.

34. Papadimitrakopoulou V: Development of PI3K/AKT/mTOR pathway inhibitors and their application in personalized therapy for non-small-cell lung cancer. J Thorac Oncol 7: 1315-1326, 2012.

35. Zhou M, Shen S, Zhao X and Gong X: Luteoloside induces G0/G1 arrest and pro-death autophagy through the ROS-mediated AKT/mTOR/p70S6K signalling pathway in human non-small cell lung cancer cell lines. Biochem Biophys Res Commun 494: 263-269, 2017. 